Research Article

\title{
Total Oxidation of Isopropanol in Its Liquid Phase, at a Low Temperature in the Presence of Prepared and Characterized Zinc Oxide
}

\author{
Younes Dehmani $(\mathbb{D}$, Abdellatif Amhoud, and Sadik Abouarnadasse \\ Laboratory of Chemistry and Biology Applied to the Environment, Moulay Ismail University, Faculty of Sciences of Meknes, \\ Meknes, Morocco \\ Correspondence should be addressed to Younes Dehmani; dehmaniy@gmail.com
}

Received 25 October 2020; Revised 21 January 2021; Accepted 28 January 2021; Published 9 February 2021

Academic Editor: Mohamed Abdel-Rehim

Copyright ( $) 2021$ Younes Dehmani et al. This is an open access article distributed under the Creative Commons Attribution License, which permits unrestricted use, distribution, and reproduction in any medium, provided the original work is properly cited.

\begin{abstract}
The complete oxidation of isopropanol in its liquid phase at a low temperature was studied in the presence of zinc oxide ( $\mathrm{ZnO}$ ). This solid was prepared with the precipitation method. Structural analysis (infrared in Fourier transform and diffraction of X-rays) and textured (adsorption/desorption of $\mathrm{N}_{2}$ ) were conducted for the wurtzite structure results, an IV type isotherm with a type H3 hysteresis. This solid presents a good catalytic activity against the complete oxidation of isopropanol, a constant of selectivity equal to 1 ; however, the studied temperatures were 40,60 , and $80^{\circ} \mathrm{C}$. In addition, a kinetic study of the oxidation was performed and showed that the reaction follows a successive mechanism isopropanol-acetone-carbon dioxide. The low value of the apparent energy of the activation of this solid confirms the high value of the initial rate of the catalytic oxidation reaction of isopropanol in the temperature range studied.
\end{abstract}

\section{Introduction}

Volatile organic compounds (VOCs) are a major source of pollution. These compounds bring together various families: alkanes, alkenes, aromatics, ketones, alcohols, acetates, aldehydes, and chlorine [1]. The volatility of these compounds gives them the ability to propagate more or less far from their place of emission, thus leading to direct (toxicity and odor) and indirect impacts [2-5] ("Smog" and warming) on the air. Concern over this observation has prompted many countries to control their emissions of gases into the atmosphere [6].

Several processes have been proposed for their destruction, and among them is the catalytic oxidation of these pollutants into carbon dioxide and water. Catalytic oxidation has many advantages over thermal oxidation, such as low cost [7]. It is, above all, profitable for treating effluents which are less concentrated in pollutants, thermal destruction then being discredited due to excessive energy consumption, in particular when the solvent content is low. However, the choice of catalyst is a very important parameter for obtaining the expected success in this type of process. This will allow the reaction rate to increase and operate at much lower temperatures [8-10].

Oxides of transition metals such as $\mathrm{Cr}, \mathrm{Fe}, \mathrm{Ni}, \mathrm{Mn}, \mathrm{Cu}$, $\mathrm{Co}$, and $\mathrm{Zn}$ are both typical and cost-effective catalysts for the complete oxidation of VOC. The properties to be attributed to this class of catalyst such as selectivity, durability, nontoxicity, and low cost (commercially accessible (approachable)) make it a considerable area of research under development [7].

The objective of our work is to test the catalytic potential of $\mathrm{ZnO}$, in the reaction of the decomposition of isopropanol in the liquid phase and at low temperature. The choice of isopropanol in this study is based on its classification among VOC. The studied transition metal oxide was prepared by the precipitation method [11]. Characterization of catalyst is carried out by physicochemical methods such as structural, 
$\mathrm{XRD}$ and FTIR, and textural, adsorption/desorption of $\mathrm{N}_{2}$ gas $[12,13]$

\section{Experimental Part}

2.1. Catalyst Preparation. A mass of zinc nitrate dihydrate $\left(\mathrm{Zn}\left(\mathrm{NO}_{3}\right)_{2} \cdot 6 \mathrm{H}_{2} \mathrm{O}\right)$ was dissolved in a volume of distilled water. To this mixture, we added $(7 \mathrm{ml} / \mathrm{min}) 20 \mathrm{ml}$ molar solution of ammonia $\left(\mathrm{NH}_{4} \mathrm{OH}\right)$ dropwise. The resulting mixture was heated with constant stirring at $40^{\circ} \mathrm{C}$ for 1 hour and then filtered in vacuum. The resulting solid was washed several times with distilled water and dried overnight in oven at $100^{\circ} \mathrm{C}$. The dried powder was calcined at $500^{\circ} \mathrm{C}$ for 3 hours [14].

\subsection{Catalyst Characterization}

(i) XRD: the patterns were recorded using an X'PERT MPD-PRO wide-angle X-ray powder diffractometer equipped with a diffracted beam monochromator and CuKa radiation filtered with $\mathrm{Ni}(\lambda=1,5406 \AA)$ $[12,13]$.

(ii) FTIR: characterization and structural changes were collected using the JASCO 4100 FTIR spectrometer with a resolution of $4 \mathrm{~cm}^{-1}$ and an accumulation of at least 64 scans $[12,13]$.

(iii) BET: BET adsorption measurements: $\mathrm{N}_{2}$ at $T=-196^{\circ} \mathrm{C}$ was carried out using a Micromeritics ASAP 2010. The specific surface area and the mean pore diameter were determined, respectively, according to the standard BET and $\mathrm{BJH}$ (Barrett, Joyner, and Halenda) $[12,13]$.

2.3. Catalytic Test. To a ball to pass lapped $250 \mathrm{ml}$, used as reactor, are added $0.15 \mathrm{~mL}$ of isopropanol (reactive), $120 \mathrm{mg}$ of catalyst, and $200 \mathrm{~mL}$ of distilled water successively. The temperature (the temperature of the water bath heating (reaction temperature) $)$ is adjusted to the desired value $\left(40^{\circ} \mathrm{C}\right.$, $60^{\circ} \mathrm{C}$, and $80^{\circ} \mathrm{C}$ ) before you plunge the ball serving reactor. Air (oxidizing reagent) is then admitted in the reactor using a lateral tubing under a flow of the order $40 \mathrm{~mL} / \mathrm{min}$ (more than enough to make the solution constantly saturated in oxygen). The reaction mixture is stirred continuously for the duration of the test in order to facilitate the accessibility of the grains of the reagent catalyst and to ensure work in chemical plan. It should be recalled that each catalytic test was performed with one taken Virgin catalyst test. The chromatographic analysis was conducted using the SHIMADZU CR15A fitted with a column under the following conditions: the column temperature is $80^{\circ} \mathrm{C}$ and $\mathrm{P}_{\mathrm{N} 2}=24.525 \mathrm{KPa}, \mathrm{P}_{\mathrm{H} 2}=39.24 \mathrm{KPa}$, and Pair $=49.05 \mathrm{KPa}[15]$.

\section{Results and Discussion}

\subsection{Catalyst Characteristics}

3.1.1. Diffraction of $X$-Rays (XRD). The sample of the solid ZnOcalcined at $500^{\circ} \mathrm{C}$ for 3 hours was analyzed by diffraction of X-rays. The diffractogram of X-rays obtained is presented in Figure 1.

The diffractogram of zinc oxide shows some peaks of diffraction at $20=31.77^{\circ}, 34.25^{\circ}, 36.25^{\circ}, 47.54^{\circ}, 57.77^{\circ}, 62.85^{\circ}$, $66.46^{\circ}, 67,93^{\circ}$, and $69^{\circ}$ that can be effected into the crystalline plan of $\mathrm{ZnO}$ (100), (002), (101), (102), (110), (103), (200), (112), and (201). All the reflexions can be indicated during $\mathrm{ZnO}$ phase hexagonal wurtzite with network constants $=0.3249 \mathrm{~nm}$ and $c=0.5205 \mathrm{~nm}$, which is accurate with the standard data (card JCPDS $\mathrm{N}^{\circ}$ 79-2205) [16]. The clearness and the intensity of the pick indicate the good crystalline nature of the prepared sample. No appearance of a line in the $\mathrm{ZnO}$ diffractogram indexed to the $\mathrm{Zn}(\mathrm{OH})_{2}$ structure, which means that $\mathrm{Zn}(\mathrm{OH})_{2}$ has been completely decomposed into $\mathrm{ZnO}$ at $500^{\circ} \mathrm{C}$ for 3 hours $[17,18]$.

3.1.2. Fourier Transform Infrared (FTIR) Spectroscopy. The FTIR spectra obtained for $\mathrm{ZnO}$ (Figure 2) show bands located at 406, 506, and $806 \mathrm{~cm}^{-1}$ characterizing $\mathrm{ZnO}$. In addition, bands located at $3420 ; 1637$, and $1385 \mathrm{~cm}^{-1}$ corresponding to the vibration of the hydroxyl group of water and carbon dioxide are also identified. [18, 19].

3.1.3. Adsorption and Desorption of $\mathrm{N}_{2}$. In heterogeneous catalysis, the catalyst activity depends on the active available surface; many settings can influence the accessibility of this surface to the catalytic oxidation reaction, such as the number of active sites, the form, and the pores' dimensions. The technique that we used to determine the specific surface is based on the physic adsorption of inert gas, generally, at the temperature of the liquid nitrogen $\left(-196^{\circ}\right)$. Figure 3 shows that the isotherm can be classified in type IV with a loop of hysteresis $\mathrm{H} 3$ depending on the classification of the UPAC. The hysteresis cycle is observed in a high relative pressure between 0.8 and 1 . This result is due to the presence of dilated pores on the prepared samples.

The presence of hysteresis sample in this isotherm is associated with the secondary process of capillary concentration, which is translated by filling completely the measured $\mathrm{P} / \mathrm{P}_{0}<1$. The diameter of the pores was calculated based on the model of Barret, Joyner, and Halenda (BJH). The results confirm the presence of mesopores of size $14.067 \mathrm{~nm}$; the Zinc oxide textural parameters are grouped in Table 1 [20].

\subsection{Catalytic Test: Catalytic Oxidation of Isopropanol}

3.2.1. Blind Test. The tests were performed without a catalyst in the same pressure and temperature conditions, which show the absence of every catalytic activity in the homogenous phase, and same results were obtained by Sahroui et al. [21].

3.2.2. Catalyst Mass Effect. We are interested in the evaluation of the impact of the mass of a catalyst on the activity of the oxidation reaction of isopropanol in its liquid phase at 


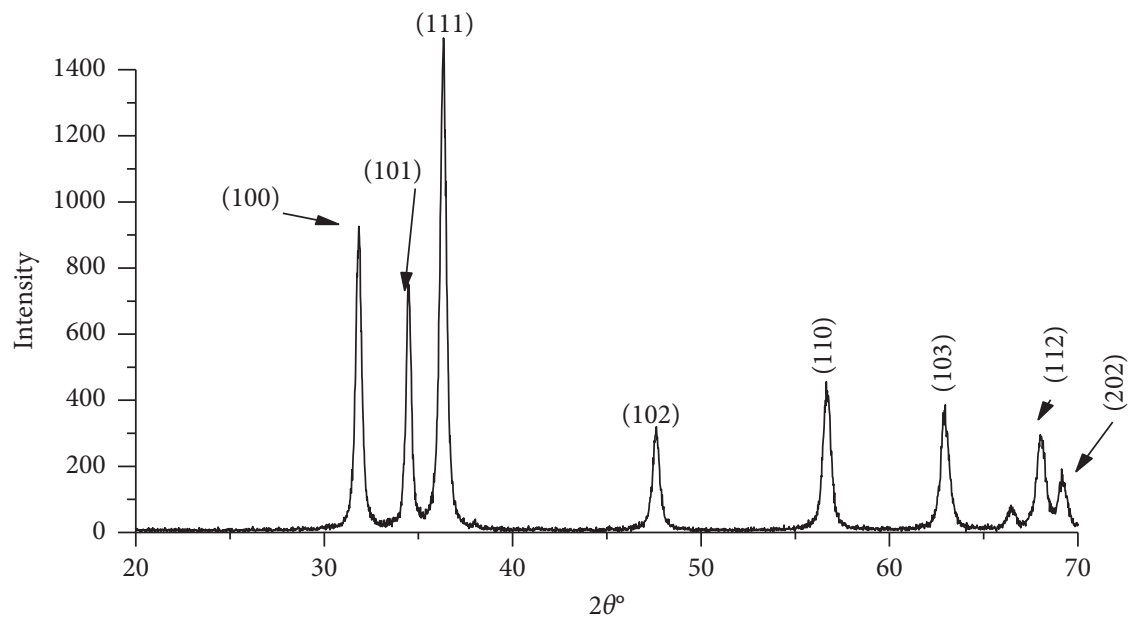

Figure 1: XRD of $\mathrm{ZnO}$.

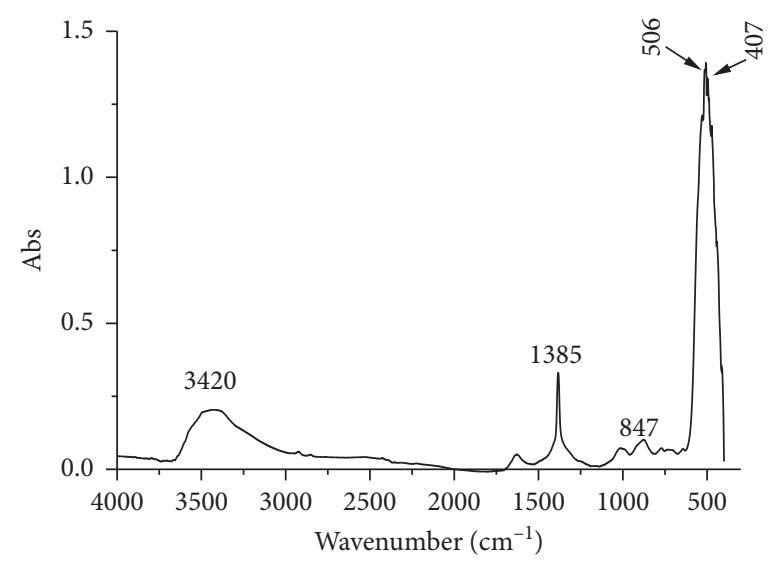

Figure 2: Spectrum of $\mathrm{ZnO}$.

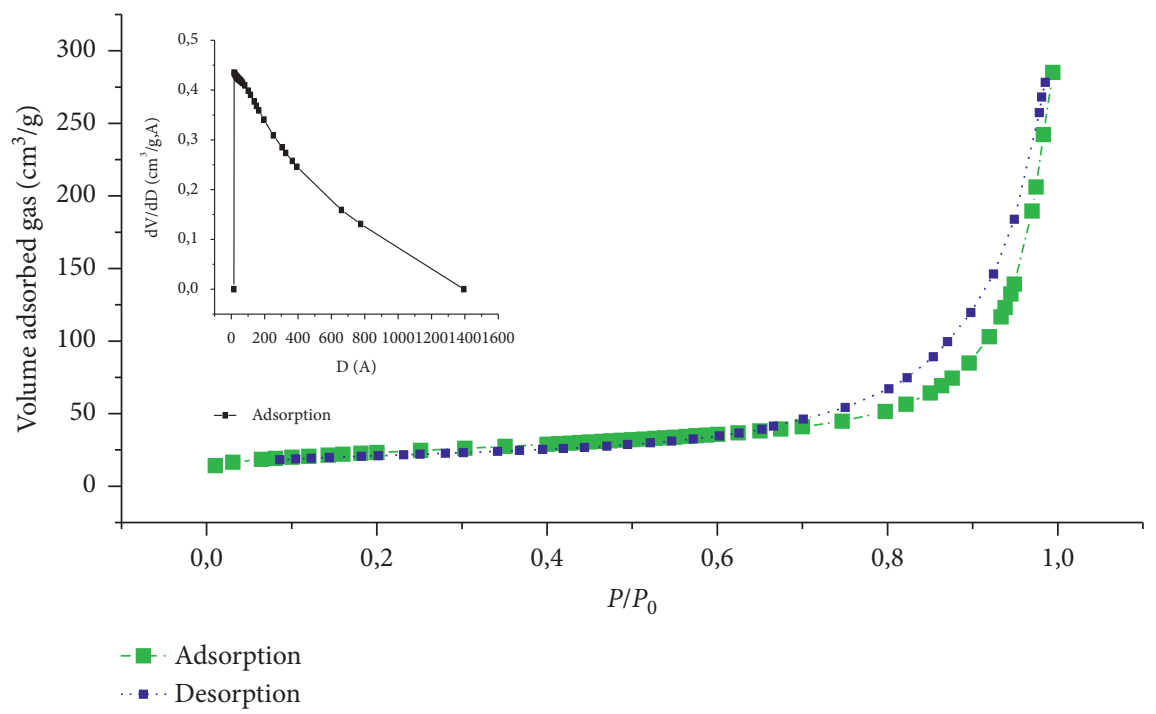

FIGURE 3: Isotherm of adsorption/desorption of $\mathrm{N}_{2}$ on $\mathrm{ZnO}$.

TABLE 1: Textural characteristics of solids. 
a low temperature of $80^{\circ} \mathrm{C}$. We tested the zinc oxide with three masses: 120,100 , and $140 \mathrm{mg}$.

The specific activity is defined as the number of moles of isopropanol disappeared per unit of time and unit of mass of the catalyst [15].

$$
a s\left(\mathrm{~mol} \cdot g^{-1} \cdot s^{-1}\right)=-\left(\frac{1}{m}\right)\left(\frac{d n}{d t}\right) \text {. }
$$

The influence of the amount of catalyst on the specific activity is illustrated in Figure 4 . The initial specific activity relating to the disappearance of isopropanol keeps a constant value whatever the amount of catalyst is. This means that, under these conditions, the catalyst operates in the chemical regime and is not the diffusion regime.

3.2.3. Evolution of the Conversion with Time. The tests of the catalytic oxidation of isopropanol's performances in the liquid phase were conducted at reaction temperatures of $40^{\circ} \mathrm{C}, 60^{\circ} \mathrm{C}$, and $80^{\circ} \mathrm{C}$ by $\mathrm{ZnO}$. The results are presented in Figure 5. The decomposition of isopropanol is catalyzed by zinc oxide conducted to the acetone, as a product of a reaction that dehydrogenates this alcohol. Figure 5 represents the evolution of the global transformation rate of isopropanol in terms of time, which indicates that this solid has good catalytic characteristics.

Zinc oxide allows a total conversion of isopropanol into carbon dioxide, and the water lasts no longer than $100 \mathrm{~min}$, $120 \mathrm{~min}$, and $140 \mathrm{~min}$ at a temperature of $80^{\circ} \mathrm{C}, 60^{\circ} \mathrm{C}$, and $40^{\circ} \mathrm{C}$. It can be concluded from this that the total destruction of isopropanol in the liquid phase is carried out rapidly at slightly moderate temperatures in the presence of this synthetic solid. These results of zinc oxide activity have been noted by many authors [22-26].

The catalyst activity concerning the disappearance of a reactive is defined by the number of the reported moles by the unit of time that disappeared at the moment of the reaction. In addition to the temperature of the reaction and the composition of the reactor's mixture, the catalytic activity depends on the nature of the catalyst and the structural textural properties. This dependence is expressed by the specific activity defined in the following. This dependence is expressed by the specific activity and defined as the ratio of the catalytic activity and the mass of catalyst as (mole/g.s) follows:

$$
\begin{aligned}
\mathrm{TT}_{\mathrm{G}} & =\frac{n_{0}-n}{n_{0}} \text { son } n=n_{0}\left(1-\mathrm{TT}_{\mathrm{G}}\right) \text { et } V=-\frac{d n}{d t} \text { est } v_{0} \\
& =n_{0} *\left(\frac{d \mathrm{TT}_{\mathrm{G}}}{d t}\right), \quad t=0, \\
\text { as } & =-\frac{d n}{d t} ! t=0=\frac{\mathrm{no}}{m c} * \frac{d \mathrm{TT}_{\mathrm{G}}}{d t} ! t=0\left(\text { mole } * g^{-1} * s^{-1}\right) .
\end{aligned}
$$

The basic characteristics of the zinc oxide aqueous solution may explain the elevated rate of acetone in the catalytic oxidation of isopropanol and a high specific activity

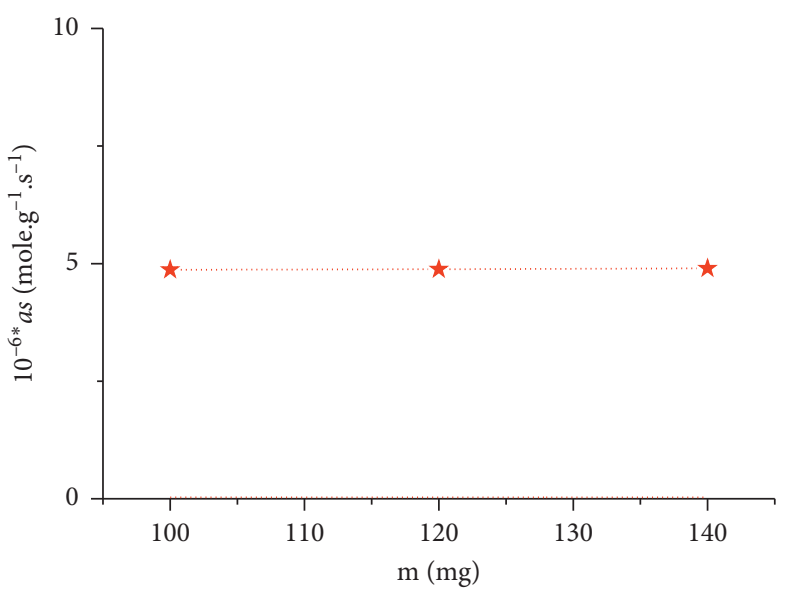

Figure 4: Mass effect on the isopropanol conversion.

that increases with temperature and a high specific activity that increases with temperature (Table 2). The obtained results show high efficiency in comparison with other works that used other catalysts that were used such as $\mathrm{Al}_{2} \mathrm{O}_{3}$, $\mathrm{Cu}_{4} \mathrm{O}_{3}$, and zeolite $\mathrm{NaX}[2,27-32]$.

\subsection{The Kinetics of the Reaction}

3.3.1. Reaction Mechanism: Variation of $T T_{G}, T T_{a c t}$ and $T T_{\mathrm{CO} 2}$. The curves of Figure 6 present the rate evolution of global transformation $\mathrm{TT}_{\mathrm{G}}$, acetone transformation $\mathrm{TT}_{\mathrm{act}}$, and carbon dioxide $\mathrm{TT}_{\mathrm{CO} 2}$ in terms of $\mathrm{TT}_{\mathrm{G}}$ through different temperatures $\left(40,60\right.$, and $\left.80^{\circ} \mathrm{C}\right)$.

The analysis of the results shows that the oxidation of isopropanol in carbon dioxide and water is complete at the temperature of $80^{\circ} \mathrm{C}$ for a reacting duration of $100 \mathrm{~min}$; also, the transformation in carbon dioxide reaches two very important values which are $97 \%$ at $60^{\circ} \mathrm{C}$ and $93 \%$ at $40^{\circ} \mathrm{C}$. The secondary product formed is acetone, with a trend higher than $72.04 \%$ at $80^{\circ} \mathrm{C}$. The significant quantity of acetone produced by the decomposition reaction of isopropanol confirms the properties of the zinc oxide surface as a base $[33,34]$. The results enable us to conclude that this catalyst presents basic sites and leads a predisposition to form acetone, a result that is confirmed in the bibliography [12]. The power of $\mathrm{ZnO}$ catalytic can be explained by the elevated capacity of transporting oxygen, as well as shifting easily between its reduced and oxidized form (the mechanism of Mars-van Krevelen) [2, 34, 35]. These curves behave the same way regardless of the temperature. The curve represents the rate of transformation of acetone in terms of the rate of global conversion pass by a maximum; therefore, the one corresponding to $\mathrm{CO}_{2}$ grams between 0 and 100 [31]. Therefore, this allows suggesting a mechanistic diagram of the form

$$
\text { Isopropanol } \Longrightarrow \text { Acetone } \Longrightarrow \text { Carbon's dioxide }+ \text { water }
$$

This was confirmed by the work of Ismagilov et al. [36] who showed that the isopropanol oxidizes in the presence of 


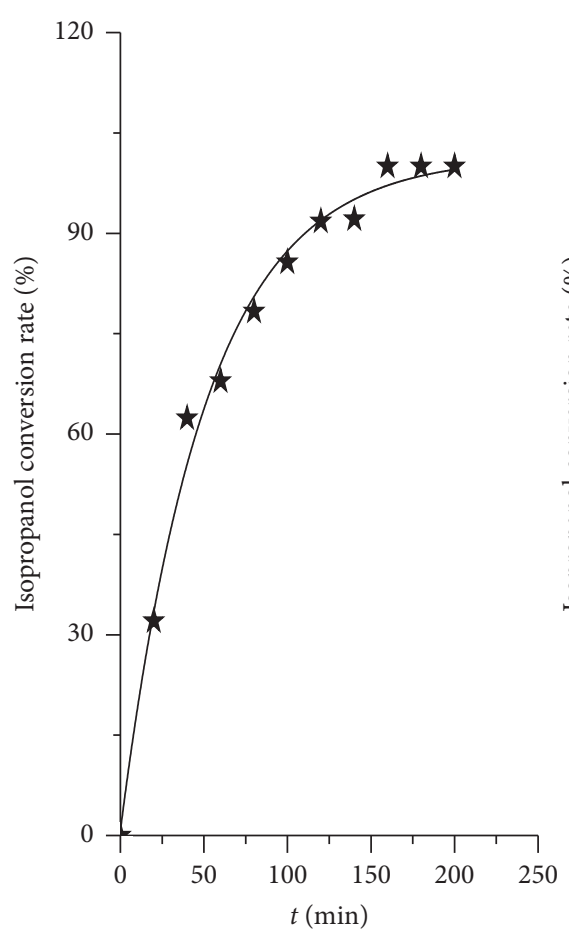

$\star 40^{\circ} \mathrm{C}$

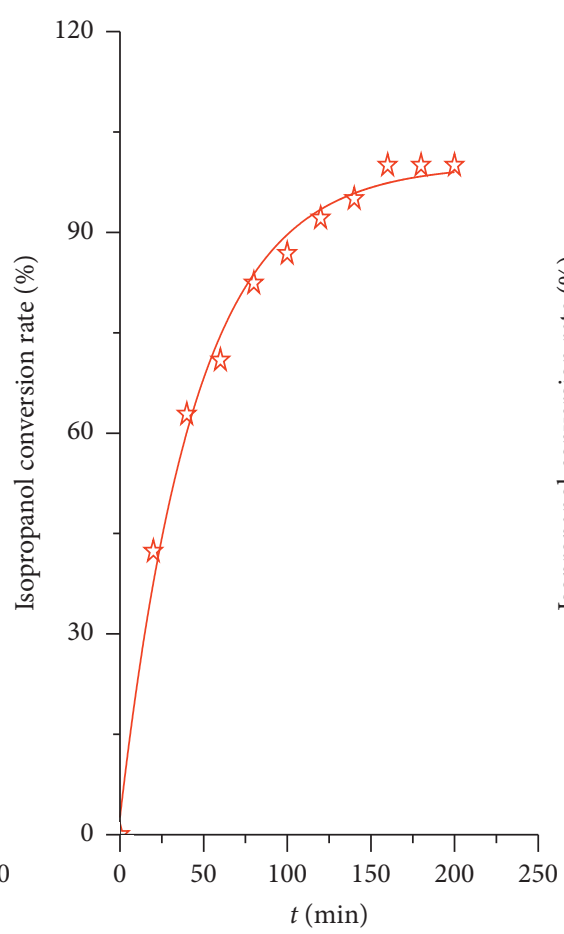

论 $60^{\circ} \mathrm{C}$

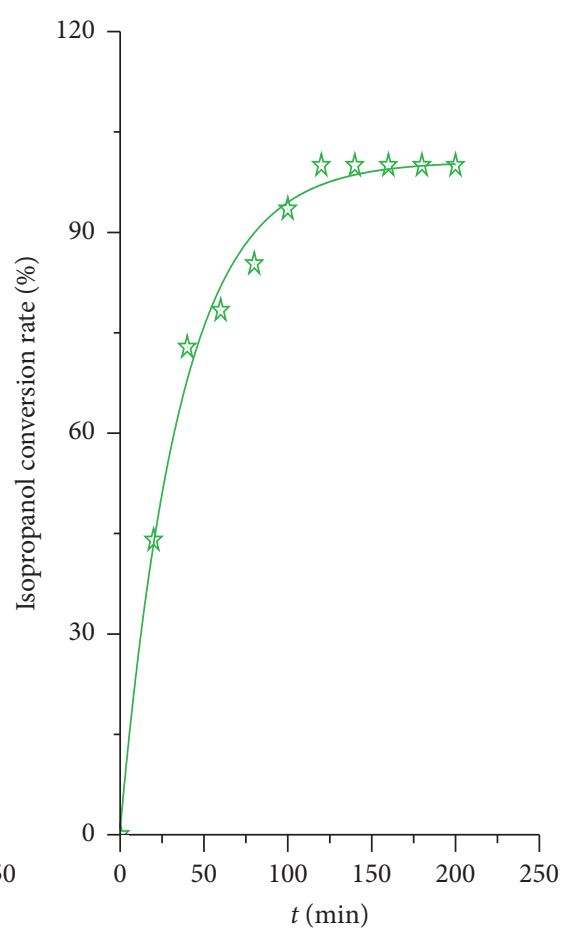

议 $80^{\circ} \mathrm{C}$

Figure 5: Rate of isopropanol transformation in terms of the presence of $\mathrm{ZnO}$.

TABLE 2: Kinetic settings of the reaction of the decomposition of isopropanol.

\begin{tabular}{|c|c|c|c|c|c|}
\hline Oxide & $\mathrm{T}^{\circ} \mathrm{C}$ & as $\left(\right.$ mole $\left.\cdot \mathrm{g}^{-1} \cdot \mathrm{s}^{-1}\right)$ & $v_{0}\left(\right.$ mole $\left.\mathrm{s}^{-1}\right)$ & $\operatorname{Ln}\left(a_{\mathrm{s}}\right)$ & $\operatorname{Ln}\left(v_{o}\right)$ \\
\hline \multirow{3}{*}{$\mathrm{ZnO}$} & 40 & 4.25E-06 & 5.09E-07 & -12.369600 & -14.4898641 \\
\hline & 60 & $4.28 \mathrm{E}-06$ & 5.13E-07 & -12.362667 & -14.4829315 \\
\hline & 80 & 4.96E-06 & $5.95 \mathrm{E}-07$ & -12.214868 & -14.3351319 \\
\hline
\end{tabular}
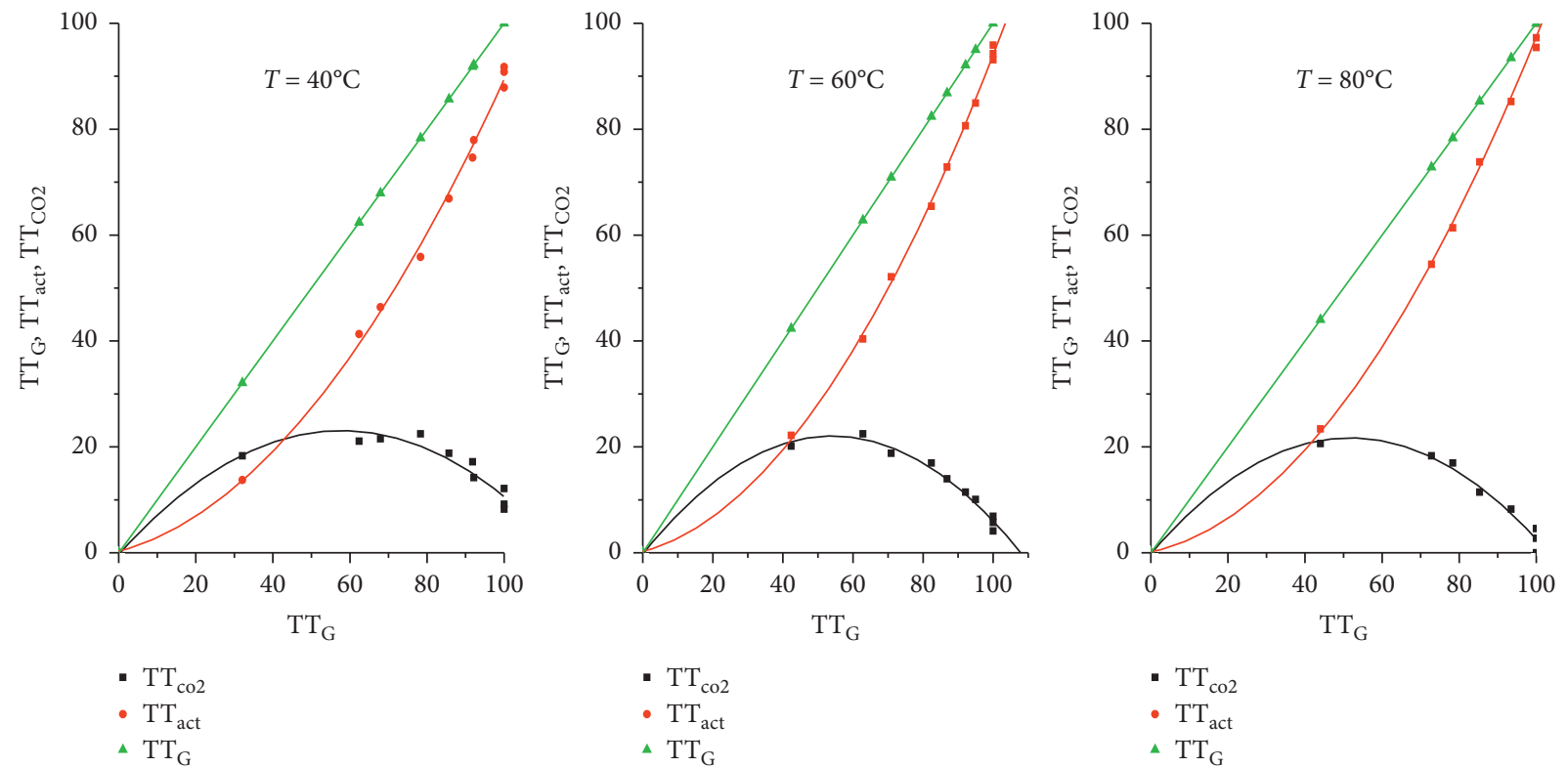

Figure 6: The rate evolution of the transformations $\mathrm{TT}_{\mathrm{G}}$ and $\mathrm{TT}$ acetone and $\mathrm{TT}_{\mathrm{CO} 2}$ in terms of $\mathrm{TT}_{\mathrm{G}}$ at different temperatures. 


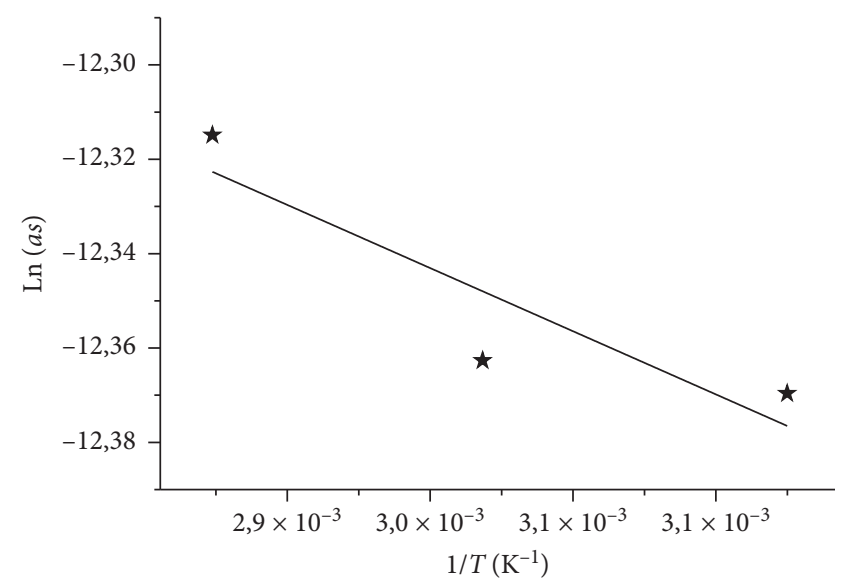

FIGURE 7: Logarithm variation of the initial speed in terms of $1 / T$ $\left(\mathrm{K}^{-1}\right)$.

the plaques of alloy $\mathrm{Al}_{2} \mathrm{O}_{3}$ and Deepak Kullkarni who used several catalysts with a base of transitioning metals such as the catalyst used in the oxidation of isopropanol for example [34].

3.3.2. Appeared Energy of Activation. The evolution curve of conversion of isopropanol that we obtained previously can be exploited to determine the kinetic parameters, such as the speed constant $k$ and the appeared energy of activation and the oxidation reaction at constant temperatures [21].

Specific activity can be expressed as $a s=A \exp (-E a / R T)$ $\mathrm{f}$, where $\mathrm{A}$ is a preexponential Arrhenius factor and $f$ a function of active constituents concentrations and catalyst mass.

Then, at constant concentrations and variable temperature, a leaner expression of temperature inverse can be written as follows:

$$
\log (a s)=\log A+\log f-\frac{E a}{R T}
$$

The relation of Arrhenius by tracing the line $\ln (a s)=\ln (A)-(E a / R * T)$.

Figure 7 presents the variation $\ln (a s)=f(1 / T)$; from this, we find the value of the appeared activation energy in the order of $3,48 \mathrm{~kJ} / \mathrm{mol}$ for zinc oxide. It has to be noted that the weakest value of the activation energy is relative to the dispersion of isopropanol and is due to the strongest value of the initial speed in the domain of the studied temperature [21]. The obtained results in this study show weak activation energy in comparison to what Deepak Kulkarni's work has shown [34]. This approves the big catalytic potential of zinc oxide.

\section{Conclusions}

In conclusion, we can conclude that the structural characteristics show a wurtzite structure, particles of this oxide with a hexagonal shape, that the textural characteristic rises, and that the isotherm is of type IV with a hysteresis loop H3.
Zinc oxide prepared by the precipitation method presents a good catalytic activity against the reaction of decomposition of isopropanol in its liquid phase with a low temperature and acetone as a mediating product. An activity of the order $4.25 \mathrm{E}-06 \mathrm{~mole} \cdot \mathrm{g}^{-1} \cdot \mathrm{s}^{-1}$ for the temperature of $40^{\circ} \mathrm{C}, 4.28 \mathrm{E}-06 \mathrm{~mole} \cdot \mathrm{g}^{-1} \cdot \mathrm{s}^{-1}$ for the temperature of $60^{\circ} \mathrm{C}$, and $4.96 \mathrm{E}-06 \mathrm{~mole} \cdot \mathrm{g}^{-1} \cdot \mathrm{s}^{-1}$ for the temperature of $80^{\circ} \mathrm{C}$ are shown.

Otherwise, the kinetic study of the reaction of the oxidation, in liquid phase of the realized isopropanol, showed that this reaction follows a successive mechanism of isopropanol.

\section{Data Availability}

All data underlying the conclusions of this study are fully available without restriction from the corresponding author on request.

\section{Conflicts of Interest}

The authors declare that they have no conflicts of interest.

\section{References}

[1] Y. Dehmani, A. A. Alrashdi, H. Lgaz, T. Lamhasni, S. Abouarnadasse, and I.-M. Chung, "Removal of phenol from aqueous solution by adsorption onto hematite $\left(\alpha-\mathrm{Fe}_{2} \mathrm{O}_{3}\right)$ : mechanism exploration from both experimental and theoretical studies," Arabian Journal of Chemistry, vol. 13, no. 5, pp. 5474-5486, 2020.

[2] R. Beauchet, J. Mijoin, I. Batonneau-Gener, and P. Magnoux, "Catalytic oxidation of VOCs on NaX zeolite: mixture effect with isopropanol and o-xylene," Applied Catalysis B: Environmental, vol. 100, no. 1-2, pp. 91-96, 2010.

[3] X. Li, L. Zhang, Z. Yang, P. Wang, Y. Yan, and J. Ran, "Adsorption materials for volatile organic compounds (VOCs) and the key factors for VOCs adsorption process: a review," Separation and Purification Technology, vol. 235, p. 116213, 2020.

[4] L. Zhu, D. Shen, and K. H. Luo, "A critical review on VOCs adsorption by different porous materials: species, mechanisms and modification methods," Journal of Hazardous Materials, vol. 389, 2020.

[5] C. Yang, "Abatement of various types of VOCs by adsorption/ catalytic oxidation: a review," Chemical Engineering Journal, vol. 370, pp. 1128-1153, 2018.

[6] Y. Dehmani and S. Abouarnadasse, "Study of the adsorbent properties of nickel oxide for phenol depollution," Arabian Journal of Chemistry, vol. 13, no. 5, pp. 5312-5325, 2020.

[7] Y. Dehmani, A. Ed-Dra, O. Zennouhi et al., "Chemical characterization and adsorption of oil mill wastewater on Moroccan clay in order to be used in the agricultural fi eld," Heliyon, vol. 6, no. 1, p. e03164, 2020.

[8] M. A. Al-ghouti, M. A. Al-kaabi, M. Y. Ashfaq, and D. A. Da'na, "Produced water characteristics, treatment and reuse: a review," Journal of Water Process Engineering, vol. 28, pp. 222-239, 2019.

[9] H. Zhang, C. Luo, and Y. Yan, "Adsorption dynamics of isopropanol in structured fixed bed with microfibrous ZSM-5 zeolite structured composite," Journal of the Taiwan Institute of Chemical Engineers, vol. 80, pp. 779-786, 2017. 
[10] Cristina Giordano "A Neglected World: Transition Metal Nitride and Metal Carbide Based Nanostructures Novel Synthesis and Future Perspectives", Chapter 2, University of Potsdam, Potsdam, Germany, 2014.

[11] B. B. Mohammed, K. Yamni, N. Tijani et al., "Adsorptive removal of phenol using faujasite-type $\mathrm{Y}$ zeolite: adsorption isotherms, kinetics and grand canonical Monte Carlo simulation studies," Journal of Molecular Liquids, vol. 296, p. 111997, 2019.

[12] H. Asnaoui, Y. Dehmani, M. Khalis, and E.-K. Hachem, "Adsorption of phenol from aqueous solutions by Na-bentonite: kinetic, equilibrium and thermodynamic studies," International Journal of Environmental Analytical Chemistry, vol. 0, no. 0, pp. 1-15, 2020.

[13] Y. Dehmani, L. Sellaoui, Y. Alghamdi et al., "Kinetic, thermodynamic and mechanism study of the adsorption of phenol on Moroccan clay," Journal of Molecular Liquids, vol. 312, p. $113383,2020$.

[14] A. Dehbi, Y. Dehmani, H. Omari et al., "Comparative study of malachite green and phenol adsorption on synthetic hematite iron oxide nanoparticles $\left(\alpha-\mathrm{Fe}_{2} \mathrm{O}_{3}\right)$," Surfaces and Interfaces, vol. 21, 2020.

[15] Y. Dehmani and S. Abouarnadasse, "Total oxidation of isopropanol in the liquid phase, under atmospheric pressure and low temperature, on transition metal oxides catalysts $\mathrm{Cr}_{2} \mathrm{O}_{3}$ and $\mathrm{Fe}_{2} \mathrm{O}_{3}$," Journal of Chemistry, vol. 2020, Article ID 6129526, 2020.

[16] M. Yang, G. Pang, L. Jiang, and S. Feng, "Hydrothermal synthesis of one-dimensional zinc oxides with different precursors," Nanotechnology, vol. 17, no. 1, pp. 206-212, 2006.

[17] R. Saravanan, V. K. Gupta, V. Narayanan, and A. Stephen, "Comparative study on photocatalytic activity of $\mathrm{ZnO}$ prepared by different methods," Journal of Molecular Liquids, vol. 181, pp. 133-141, 2013.

[18] J. Kaur, S. Bansal, and S. Singhal, "Photocatalytic degradation of methyl orange using $\mathrm{ZnO}$ nanopowders synthesized via thermal decomposition of oxalate precursor method," Physica B: Condensed Matter, vol. 416, pp. 33-38, 2013.

[19] H. Wang, C. Xie, W. Zhang, S. Cai, Z. Yang, and Y. Gui, "Comparison of dye degradation efficiency using $\mathrm{ZnO}$ powders with various size scales," Journal of Hazardous Materials, vol. 141, no. 3, pp. 645-652, 2007.

[20] K. T. Alali, T. Liu, J. Liu et al., "Preparation and characterization of $\mathrm{ZnO} / \mathrm{CoNiO}_{2}$ hollow nanofibers by electrospinning method with enhanced gas sensing properties," Journal of Alloys and Compounds, vol. 702, pp. 20-30, 2017.

[21] H. Sahraoui, S. Abouarnadasse, K. Elkamel, A. Nadiri, and A. Yacoubi, "Étude de l'activité catalytique d'une diatomite naturelle marocaine dans la réaction de décomposition de l'isopropanol," Annales de Chimie Science des Matériaux, vol. 28 , no. 4, pp. 91-105, 2003.

[22] M. Sadiq, K. Saeed, S. Sadiq, S. Munir, and M. Khan, "Liquid phase oxidation of cinnamyl alcohol to cinnamaldehyde using multiwall carbon nanotubes decorated with zinc-manganese oxide nanoparticles," Applied Catalysis A: General, vol. 539, pp. 97-103, 2017.

[23] A. Król, P. Pomastowski, K. Rafińska, V. Railean-Plugaru, and B. Buszewski, "Zinc oxide nanoparticles: synthesis, antiseptic activity and toxicity mechanism," Advances in Colloid and Interface Science, vol. 249, pp. 37-52, 2017.

[24] Z. Q. Liu, J. Tu, Q. Wang et al., "Catalytic ozonation of diethyl phthalate in aqueous solution using graphite supported zinc oxide," Separation and Purification Technology, vol. 200, pp. 51-58, 2018.
[25] D. Ali, Y. Dehmani, H. Omari, A. Lamini, K. Elazhari, and A. Abdallaoui, "Hematite iron oxide nanoparticles $\left(\alpha-\mathrm{Fe}_{2} \mathrm{O}_{3}\right)$ : synthesis and modelling adsorption of malachite green "," Journal of Environmental Chemical Engineering, vol. 8, no. 1, p. 103394, 2020.

[26] Y. Dehmani, H. Lgazb, A. A. Alrashdi, T. Lamhasni, S. Abouarnadasse, and I.-M. Chung, "Phenol adsorption mechanism on the zinc oxide surface: experimental, cluster DFT calculations, and molecular dynamics simulations," Journal of Molecular Liquids, vol. 324, 2021.

[27] H. Chen, H. Zhang, and Y. Yan, "Gradient porous $\mathrm{Co}-\mathrm{Cu}-\mathrm{Mn}$ mixed oxides modified ZSM-5 membranes as high efficiency catalyst for the catalytic oxidation of isopropanol," Chemical Engineering Science, vol. 111, pp. 313-323, 2014.

[28] W. Zhou, C. Wang, J. Xu, Y. Du, and P. Yang, "Enhanced electrocatalytic performance for isopropanol oxidation on Pd$\mathrm{Au}$ nanoparticles dispersed on poly ( $\mathrm{p}$-phenylene) prepared from biphenyl," Materials Chemistry and Physics, vol. 123, no. 2-3, pp. 390-395, 2010.

[29] A. Ghosh, K. Bhaduri, S. Shah, A. Auroux, J. K. Pandey, and B. Chowdhury, "Dehydration of isopropanol to propylene over fullerene $\left[\mathrm{C}_{60}\right]$ containing niobium phosphate catalyst: study on catalyst recyclability," Molecular Catalysis, vol. 475, p. 110470, 2019.

[30] O. N. Fedyaeva, D. O. Artamonov, and A. A. Vostrikov, "Effect of $\mathrm{H}_{2} \mathrm{O}$ and $\mathrm{CO}_{2}$ on propane, propene, and isopropanol oxidation at elevated pressures," Combustion and Flame, vol. 199, pp. 230-240, 2019.

[31] J. Medina-Valtierra, C. Frausto-Reyes, G. CamarilloMartínez, and J. A. Ramírez-Ortiz, "Complete oxidation of isopropanol over $\mathrm{Cu}_{4} \mathrm{O}_{3}$ (paramelaconite) coating deposited on fiberglass by CVD," Applied Catalysis A: General, vol. 356, no. 1, pp. 36-42, 2009.

[32] J. Abelleira, J. Sánchez-Oneto, J. R. Portela, and E. J. Martínez de la Ossa, "Kinetics of supercritical water oxidation of isopropanol as an auxiliary fuel and co-fuel," Fuel, vol. 111, pp. 574-583, 2013.

[33] J. Karuppiah, L. Sivachandiran, R. Karvembu, and C. Subrahmanyam, "Catalytic nonthermal plasma reactor for the abatement of low concentrations of isopropanol," Chemical Engineering Journal, vol. 165, no. 1, pp. 194-199, 2010.

[34] D. Kulkarni and I. E. Wachs, "Isopropanol oxidation by pure metal oxide catalysts: number of active surface sites and turnover frequencies," Applied Catalysis A: General, vol. 237, no. 1-2, pp. 121-137, 2002.

[35] S. Xing, Z. Liu, Q. Xue et al., "Rh nanoroses for isopropanol oxidation reaction," Applied Catalysis B: Environmental, vol. 259, p. 118082, 2019.

[36] I. Z. Ismagilov, E. M. Michurin, and O. B. Sukhova, "Oxidation of organic compounds in a microstructured catalytic reactor," Chemical Engineering Journal, vol. 135, no. SUPPL. 1, pp. S57-S65, 2007. 